José Carlos Zebulum ${ }^{1}$

\title{
DECISÕES JUDICIAIS NA SAÚDE, UM CAMPO PROPÍCIO PARA A INTERFERÊNCIA DE CONVICÇÕES PESSOAIS DE CADA JUIZ: ANÁLISE DA JURISPRUDÊNCIA DE QUATRO TRIBUNAIS DE JUSTIÇA
}

Judicial decisions in healthcare, a propitious field to the interference of personal beliefs of each judge: Analysis of the jurisprudence of four courts

${ }^{1}$ Universidade Federal do Rio de Janeiro. Rio de Janeiro/RJ, Brasil. Correspondência: jcarloszebulum@gmail.com

Recebido em: 01/02/2017. Aprovado em: 03/04/2017. 


\section{RESUMO}

A partir da expansão do fenômeno da judicialização da saúde, os juízes vêm assumindo um importante papel na concretização do direito à saúde em nosso país. Nesse contexto, os magistrados de todas as instâncias do Poder Judiciário brasileiro passam a se defrontar com questões inusitadas inerentes à garantia efetiva do acesso aos serviços de saúde, o que suscitou, em alguns casos, diferentes posicionamentos e intensas discussões nos tribunais estaduais e federais brasileiros. Algumas questões de saúde pública levadas com frequência à apreciação dos juízes geram, de fato, intensas controvérsias, que não decorrem de uma simples oposição de interesses entre o poder público e o particular requerente, mas sim do fato de o magistrado, no momento de decidir, sofrer forte influência de seus próprios princípios morais, e nem sempre se sentir "confortável” em adotar a solução eventualmente apontada pela mera aplicação da lei. Trata-se de situações em que os juízes acabam decidindo mais em função de suas convicções pessoais, de sua sensibilidade, enquanto ser humano, à dor e ao sofrimento alheios, do que em função de seus conhecimentos técnico-jurídicos. O objetivo deste estudo é verificar como questões dessa natureza vêm sendo enfrentadas e decididas no âmbito de quatro tribunais estaduais de justiça do país.

\section{Palavras-Chave}

Conflitos Morais; Direito à Saúde; Judicialização; Jurisprudência; Tribunais Estaduais de Justiça.

\section{ABSTRACT}

Since the expansion of the phenomenon of health judicialization, judges have assumed an important role in the consolidation of the right to healthcare in Brazil. In this context, magistrates from all levels of the Brazilian judiciary system are faced with unusual issues inherent to assuring effective access to health services, which has led in some cases to different positions and intense discussions in state and federal Brazilian courts. Some public health issues taken daily to the judges assessment, in fact, generate intense controversies that do not arise from a simple opposition of interests between government and the particular claimant, but by the fact that the magistrate, when deciding, is strongly influenced by his or her own moral principles, and will not always feel "comfortable" in adopting the solution suggested by simple law enforcement. These are situations in which judges end up deciding more according to their personal convictions, their sensitivity as human beings to the pain and suffering of others, than to their technical-legal knowledge. The objective of this study is to verify how questions of this nature have been confronted and decided in the jurisprudence of four state courts of law in Brazil.

\section{Keywords}

Judicialization; Jurisprudence; Moral Conflicts; Right to Health; State Courts of Law. 


\section{Introdução}

A partir da expansão do fenômeno da judicialização da saúde, os juízes vêm assumindo um importante papel na concretização do direito à saúde no Brasil. É fato notório que boa parte dos serviços de saúde prestados pelos órgãos públicos não atende às demandas da população e acaba sendo objeto de ações judiciais, que se proliferam aos milhares nas cortes estaduais e federais de todo o país. Assim, a matéria, que até então não fazia parte do cotidiano dos tribunais, ingressa no debate jurídico, constituindo hoje um importante foco de atenção e preocupação de juristas e operadores do direito. Já nos anos 1990, observava-se o crescimento exponencial do número de ações judiciais propostas em face do poder público com o fim de garantir o fornecimento de medicamentos e a realização de cirurgias e procedimentos ${ }^{1}$. A incorporação de novas tecnologias no âmbito do Sistema Único de Saúde (SUS) também passou a ser motivo de preocupação entre gestores da saúde em todos os níveis federativos.

Não existia à época, como não existe hoje, um levantamento em âmbito nacional da dimensão do fenômeno de judicialização, tampouco de seu impacto sobre todo o SUS e seus usuários. Isso se dá, em grande medida, pelo fato de as ações propostas estarem divididas entre a justiça federal e a justiça de cada estado da Federação - espaços autônomos de decisão, com organização própria e características de demandas, em certa medida, particularizadas. Conquanto não se tenha uma informação precisa acerca da evolução do número de ações judiciais de saúde em trâmite, os dados fornecidos pela consultoria jurídica junto ao Ministério da Saúde indicam um crescimento progressivo no número de ações propostas, ano a ano. De fato, só na justiça federal no ano de 2009 foram recebidas 10.486 novas ações; em 2010, 11.203; em 2011, 12.436; e, em 2012, 13.051 novas ações².

Levantamento realizado pelo Conselho Nacional de Justiça (CNJ) revelou que, em setembro de 2010, tramitava nas várias instâncias do Poder Judiciário estadual e federal - um total de 240.890 ações, sem contar os dados dos tribunais dos estados do Amazonas, Paraíba e Pernambuco, que não enviaram informações ${ }^{3}$. Segundo informa a Advocacia-Geral da União (AGU), não há elementos seguros

\footnotetext{
${ }^{1}$ CHIEFFI, Ana Luiza; BARATA, Rita de Cássia Barradas. Ações judiciais: estratégia da indústria farmacêutica para introdução de novos medicamentos. Revista de Saúde Pública, São Paulo, v. 44, n. 3, jun. 2010. Disponível em: <http://www.scielo.br/scielo.php?script=sci_arttext\&pid=S0034-89102010000300005>. Acesso em: 21 jan. 2017.http://dx.doi.org/10.1590/S0034-89102010000300005.

${ }^{2}$ MINISTÉRIO DA SAÚDE. Intervenção judicial na saúde pública: panorama no âmbito da Justiça Federal e apontamentos na seara das Justiças Estaduais. Brasília-DF, 2013. Disponível em: <http://u.saude.gov. br/images/pdf/2014/maio/29/Panorama-da-judicializa----o--2012---modificado-em-junho-de-2013.pdf>. Acesso em: 7 jul. 2016.

${ }^{3}$ BALESTRA NETO, Otávio. A jurisprudência dos tribunais superiores e o direito à saúde - evolução rumo à racionalidade. Revista de Direito Sanitário, Brasil, v. 16, n. 1, p. 87-111, jul. 2015. ISSN 2316-9044. Disponível em: <http://www.revistas.usp.br/rdisan/article/view/100025>. Acesso em: 21 jan. 2017. http://dx.doi.org/10.11606/issn.2316-9044.v16i1p87-111.
} 
para aferir a razão do crescimento numérico das ações judiciais em face da União, mas estima o órgão que a grande probabilidade de sucesso nessas demandas, em que a antecipação dos efeitos da tutela é quase sempre concedida, e em caráter irreversível, associada ao fenômeno da interiorização da justiça federal, são os fatores que melhor explicam essa evolução.

Nesse contexto, os magistrados de todas as instâncias do Poder Judiciário brasileiro passam a se defrontar com questões inusitadas inerentes à garantia efetiva do acesso aos serviços de saúde, o que suscitou, em alguns casos, diferentes posicionamentos e intensas discussões nos tribunais estaduais e federais do país ${ }^{4}$.

A relevância do tema e a complexidade da discussão sobre o fornecimento de tratamentos e medicamentos por parte do poder público em virtude de determinação judicial fizeram com que o Supremo Tribunal Federal (STF) avocasse para si a discussão da problemática envolvida no fenômeno da judicialização da saúde, reconhecendo, por unanimidade, a existência de repercussão geral de questão constitucional, a partir do Recurso Extraordinário n. 566.471, interposto pelo Estado do Rio Grande do Norte. Com base nesta decisão, o então presidente do STF, ministro Gilmar Mendes, convocou uma audiência pública, que foi realizada entre 27 de abril e 7 de maio de 2009, com o objetivo de ampliar o debate e compartilhar informações com diversos interessados. Na ocasião, foram ouvidos diversos especialistas em matéria de saúde pública, especialmente gestores públicos, membros da magistratura, do Ministério Público, da Defensoria Pública, da AGU, estados e municípios, além de acadêmicos e entidades e organismos da sociedade civil. A intenção do relator era de que as considerações, os argumentos e as propostas apresentados nos debates pudessem ser utilizados para a instrução de qualquer processo, tanto no âmbito do STF como também por qualquer outra serventia do país, desde que solicitadas. A preocupação da cúpula do Poder Judiciário de definir balizamentos para uma série de questões referentes ao direito à saúde reflete a intensa controvérsia que já se estabelecia sobre pontos importantes da matéria, o que dava margem a orientações e decisões divergentes no âmbito de cada tribunal. Como consequência, a inevitável ofensa aos princípios da isonomia e da segurança jurídica abala a credibilidade do Poder Judiciário e estimula a litigiosidade e a recorribilidade das decisões ${ }^{5}$.

Algumas questões de saúde pública levadas frequentemente à apreciação dos juízes geram, de fato, intensas controvérsias, que não decorrem de uma simples oposição de interesses entre o poder público e o particular requerente, mas sim do

\footnotetext{
${ }^{4}$ VENTURA, Miriam. O processo decisório judicial e a assessoria técnica: a argumentação jurídica e médicosanitária na garantia do direito à assistência terapêutica no SUS. Tese (Doutorado) - Escola Nacional de Saúde Pública Sergio Arouca, Rio de Janeiro, 2012. Disponível em: <http://bases.bireme.br/cgi-bin/ wxislind.exe/iah/online/?IsisScript=iah/iah.xis\&src=google\&base=LILACS\&lang=p\&nextAction=Ink\&exprS earch=745021\&indexSearch=ID>. Acesso em: 10 nov. 2016.

${ }_{5}^{5}$ STF. Agravo Regimental na Suspensão de Tutela Antecipada n. 175/CE, Tribunal Pleno, Relator Ministro Gilmar Mendes (Presidente),17/03/2010, DJe 30/04/2010, p. 070.
} 
fato de o magistrado, no momento de decidir, sofrer forte influência de suas convicções pessoais, de seus próprios princípios morais, e nem sempre se sentir "confortável” em adotar a solução eventualmente apontada pela simples aplicação da lei - quando a lei não for omissa em relação a esses casos. Experimenta, portanto, situações de conflito moral, assim entendidas como aquelas em que dois ou mais interesses legítimos estão em conflito que não pode ser dirimido, a priori, sem que haja a necessária ponderação dos interesses envolvidos ${ }^{6}$. São casos em que os juízes são instados a deliberar sobre situações cuja solução não depende de maiores divagações sobre as normas e os princípios jurídicos, mas que poderão desafiar seus valores enquanto pessoa, sua conviçção sobre a justiça, sobre o certo e o errado. Assim, os juízes acabam deixando seus conhecimentos técnico-jurídicos em segundo plano e decidindo mais em função de suas convicções pessoais, de sua sensibilidade, enquanto seres humanos, à dor e ao sofrimento alheios.

Não é difícil identificar, dentre as diversas questões levadas diariamente ao conhecimento do Poder Judiciário em demandas de saúde, uma ampla variedade de situações com potencial para gerar conflitos dessa natureza. Com efeito, seja pela elevada envergadura do direito envolvido - a saúde ou a própria vida humana -, seja pelas consequências que podem resultar das deliberações no caso concreto, os juízes, nesses casos, decidem mais em função de sua sensibilidade. São emblemáticas as seguintes situações: (i) submete-se à apreciação do juiz pedido de fornecimento de medicamento ou tratamento que causará um grande impacto no orçamento do ente público envolvido; (ii) submete-se à apreciação do juiz, com justificativa de urgência lastreada em laudo médico, pedido liminar de fornecimento de prestação de saúde não registrada na Agência Nacional de Vigilância Sanitária (Anvisa), fora dos casos excepcionalmente admitidos na legislação; (iii) submete-se à apreciação do juiz, com justificativa de urgência lastreada em laudo médico, pedido liminar de fornecimento de prestação de saúde cujo procedimento não consta da tabela de procedimentos do SUS nem está previsto em protocolos clínicos e diretrizes terapêuticas do SUS; (iv) em demanda para fornecimento de prestação de saúde, o juiz, em função do que determinam as regras de natureza processual, se vê obrigado a declinar de sua competência para outro foro, o que provocará retardamento incompatível com a urgência comprovada nos autos; (v) em que pese a determinação legal para realização de audiência de conciliação e mediação, a parte autora, diante da postura reiterada dos advogados públicos de se recusarem terminantemente a qualquer tentativa de conciliação, requer ao magistrado que a audiência não seja designada; (vi) usuário que se encontra em fila de espera para tratamento médico-cirúrgico em hospital público, mediante justificativa de comprovado agravamento de seu quadro clínico,

\footnotetext{
${ }^{6}$ Conforme FREITAG, Barbara. A questão da moralidade: da razão prática de Kant à ética discursiva de Habermas. Tempo Social - Rev. Sociologia da USP, v. 1, n. 2, p. 1-32, jul./dez 1989. Disponível em: <http:// www.scielo.br/scielo.php?script=sci_arttext\&pid=S0103-20701989000200007\&lng=en\&nrm=iso $>$. Acesso em: 21 jan. 2017.http://dx.doi.org/10.1590/ts.v1i2.84764.
} 
busca o provimento jurisdicional para obter prioridade de atendimento em relação aos demais; (vii) o juiz verifica que a lei, ou os entendimentos jurisprudenciais que orientam a resolução do feito, revela-se anacrônica; (viii) submete-se à apreciação do juiz pedido de fornecimento de medicamento ou tratamento de saúde de alto custo, que implicaria grave lesão às finanças públicas, a um usuário terminal, sem chance de cura, apenas para aumentar a sobrevida; (ix) usuário com elevado nível de renda familiar requer, judicialmente, fornecimento de determinada prestação de saúde pelo SUS; (x) diante de pedido para fornecimento de determinado tratamento, o Núcleo de Apoio Técnico (NAT) informa ao juiz que há pouca literatura sobre o tema, com resultados imprecisos e alguns mostrando, inclusive, que essa prática pode piorar o quadro clínico do usuário; (xi) usuário idoso, com quadro clínico grave, já internado em hospital da rede privada, requer transferência com urgência a hospital público especializado, onde poderá receber melhor atendimento, porém, segundo o laudo médico, a transferência coloca em risco sua vida; e (xii) a parte autora requer concessão de antecipação da tutela, no sentido de que lhe seja assegurado o direito ao fornecimento de determinado medicamento conforme prescrição médica; o juiz designa a realização de perícia, mas o autor não comparece, argumentando dificuldades de deslocamento; a advocacia pública requer a extinção do feito sem resolução do mérito, caracterizada a ausência de interesse processual.

Assim, interessa verificar como os juízes decidem e fundamentam suas decisões nesses casos em que são desafiados em suas crenças, conviç̧ões e princípios morais. Isso porque, conforme disposto no artigo 93, inciso IX, da Constituição Federal $(\mathrm{CF} / 1988)^{7}$, os juízes, ao proferirem suas decisões, devem efetivamente fundamentar suas decisões, sob pena de nulidade, e, como adverte Manuel Atienza ${ }^{8}$, esta atividade deve estar lastreada em regras científicas. Portanto, se um juiz apresentar como justificativa de sua decisão suas convicções religiosas ou seu entendimento particular sobre o que é correto ou justo, não está fundamentando nem justificando sua decisão, mas somente explicando-a. É evidente a dificuldade que o juiz experimenta ao tentar conferir um lastro técnico-jurídico, como impõe a CF/1988, a uma decisão que proferiu simplesmente com base em suas convicções morais.

Em importante debate doutrinário, Richard A. Posner e Ronald Dworkin abordaram a questão do enfrentamento de questões morais pelos juízes, o primeiro defendendo que tais questões devem ser simplesmente ignoradas pelos juízes, que dispõem de melhores recursos para atingir seus objetivos. Segundo Posner ${ }^{9}$, na Inglaterra, o direito é uma disciplina autônoma, e tais questões são resolvidas, em grande parte, pela interpretação de textos autorizados, que consistem em leis, regulamentações

7BRASIL. Constituição da República Federativa do Brasil. Disponível em: <http://www.planalto.gov.br/ ccivil_03/constituicao/constituicaocompilado.htm>. Acesso em: 22 jan. 2019.

${ }^{8}$ ATIENZA, Manuel. Razões do direito: teorias da argumentação jurídica. 3. ed. São Paulo: Landy, 2003.

${ }^{9}$ POSNER, Richard A. The problematic of moral and legal theory. 3. ed. Harvard: Harvard University Press, 2009 
e decisões judiciais, sendo certo que nenhuma destas fontes incorpora uma teoria moral. Defendendo posicionamento oposto, Dworkin ${ }^{10}$ adverte que, se os juízes são obrigados a lidar com questões morais, como dizer que devem resolvê-las por meio da história, da economia, da álgebra ou de qualquer outra técnica que não a moral?

Na prática, o que se verifica nesses casos é que a argumentação utilizada para fundamentar as decisões afasta-se, invariavelmente, do tradicional discurso técnico-jurídico, evidenciando-se claramente um discurso moral. Desta forma, a existência desses conflitos íntimos do magistrado poderá ser revelada por alguns indícios, a serem observados na argumentação utilizada em suas decisões:

(a) Utilização de expressões de menor densidade jurídica que demonstrem uma avaliação puramente subjetiva, tais como "é razoável”, "não é proporcional”, “é justo" etc.

(b) Adoção de critérios que mais expressam sentimentos humanitários de solidariedade, justiça e preocupação com o bem-estar do próximo, que, embora louváveis, revelam-se distantes de qualquer acepção técnico-jurídica. Nesta linha, algumas decisões são justificadas pelo intuito de proteger os mais pobres, as crianças, os portadores de deficiência etc.

(c) A simples utilização de princípios gerais do direito de forma vaga e imprecisa, que aparecem como formulações genéricas hábeis a justificar toda e qualquer decisão, sem que haja o enfrentamento efetivo das peculiaridades do caso concreto.

(d) Recurso a fontes doutrinárias que militam no campo da Filosofia, estranhas ao ramo do direito.

Além desses indícios a serem observados na argumentação utilizada nas decisões judiciais, a existência de conflitos morais experimentados pelos juízes também pode ser evidenciada a partir da verificação de soluções radicalmente diferentes para casos idênticos. É bem verdade que uma certa oscilação da jurisprudência, decorrente, no mais das vezes, de diferentes interpretações conferidas à lei, é sempre esperada e considerada normal. Entretanto, diante de situações em que cada magistrado decidirá de acordo com seus princípios e convicções pessoais, que nem sempre coincidirão com aqueles adotados por seus pares, a divergência entre posicionamentos deverá assumir uma amplitude ainda mais significativa.

Com base nestas premissas, o objetivo deste estudo é verificar a presença de tais indícios em decisões proferidas no âmbito de quatro tribunais estaduais de justiça do país ao se defrontarem com uma questão típica de saúde, identificando, assim, possíveis situações de conflito enfrentadas pelos juízes.

${ }^{10}$ DWORKIN, Ronald. A justiça de toga. São Paulo: Martins Fontes, 2010. 


\section{Método}

Para atingir o objetivo acima descrito, realizou-se uma pesquisa jurisprudencial de caráter documental que consistiu em um estudo seccional retrospectivo de decisões do Poder Judiciário Estadual, colhidas nas bases de dados de quatro tribunais de justiça do país: Rio de Janeiro, São Paulo, Minas Gerais e Rio Grande do Sul. As cortes foram selecionadas tendo em vista a existência de importantes cidades brasileiras alocadas sob as respectivas jurisdições. Adotando-se a técnica de análise de conteúdo, foi selecionada inicialmente uma questão da área da saúde com reconhecido potencial para desafiar as convicções morais dos magistrados e corriqueiramente enfrentada em demandas judiciais de saúde no âmbito dos tribunais de justiça identificados. Eis a questão:

Usuário que apresenta quadro de doença que não vem respondendo aos tratamentos oferecidos pelo SUS requer judicialmente, com base em prescrição médica, o fornecimento de determinado medicamento sem registro ou autorização da Anvisa.

Note que, no caso, tem-se como pano de fundo uma evidente questão moral a ser resolvida, que diz respeito à preservação da saúde e da vida de uma pessoa que, de acordo com parecer médico, está a depender de determinado medicamento que, em princípio, revela-se eficaz no tratamento da doença, mas que sequer se encontra registrado na Anvisa - e, como se sabe, a Lei n. 8.080/1990, artigo 19-T, inciso II, veda, peremptoriamente, a dispensação, o pagamento, o ressarcimento ou o reembolso de medicamento e produto, nacional ou importado, sem registro na autarquia federal ${ }^{11}$.

Observe-se, no entanto, como ressaltou o ministro Gilmar Mendes no julgamento da STA 175 AgR/CE:

[...] essa não é uma regra absoluta. Em casos excepcionais, a importação de medicamento não registrado poderá ser autorizada pela Anvisa. A Lei n. 9.782/99, que criou a Agência Nacional de Vigilância Sanitária (Anvisa), permite que ela dispense de registro medicamentos adquiridos por intermédio de organismos multilaterais internacionais, para uso de programas em saúde pública pelo Ministério da Saúde ${ }^{12}$.

Têm-se, assim, dois importantes interesses a serem ponderados pelo magistrado no enfrentamento da questão, gerando a situação de conflito moral nos termos mencionados:

\footnotetext{
${ }^{11}$ BRASIL. Lei n. 8.080, de 19 de setembro de 1990. Dispõe sobre as condições para a promoção, proteção e recuperação da saúde, a organização e o funcionamento dos serviços correspondentes e dá outras providências. Disponível em: <https://www.planalto.gov.br/ccivil_03/leis/L8080.htm>. Acesso em: 29 dez 2016.

${ }^{12}$ STF. STA 175 AgR/CE, Tribunal Pleno, Rel. Min. GILMAR MENDES (Presidente), julgamento: 17/03/2010, DJe 30/04/2010, p. 070.
} 
(a) A preservação da saúde e da vida humana, que, segundo a prescrição médica que acompanha o pedido, dependem do fornecimento do medicamento em questão.

(b) A submissão das decisões do juiz ao princípio da legalidade, considerando que a lei, a princípio, veda o fornecimento do medicamento nessas condições e que a inexistência de registro na Anvisa põe em dúvida a própria segurança e eficácia do medicamento.

Prosseguindo a pesquisa, verificou-se como vêm sendo enfrentadas e decididas nos tribunais selecionados as demandas judiciais que tenham por objeto a referida questão. A busca realizada nas páginas eletrônicas dos quatro tribunais de justiça selecionados utilizou, como argumentos de busca, os seguintes descritores: "medicamento", "registro", "anvisa", "fornecimento" e "público". A técnica adotada permitiu uma abordagem comparativa sobre como a matéria vem sendo enfrentada pelos magistrados de cada um dos tribunais estaduais selecionados, para se concluir a respeito da interferência de convicções pessoais dos juízes na apreciação da referida questão ${ }^{13}$.

A busca e a análise dos dados jurisprudenciais foram realizadas ao longo do mês de janeiro de 2017, nas páginas eletrônicas dos tribunais de justiça dos estados do Rio de Janeiro, São Paulo, Minas Gerais e Rio Grande do Sul. Quanto aos critérios de inclusão, compuseram o universo do estudo as decisões judiciais proferidas em agravos de instrumento, agravos internos, apelações, remessas necessárias, embargos infringentes e embargos de declaração no período de 01/01/2014 a 31/12/2016 - que se revelou suficiente para proporcionar uma base de dados satisfatória para os objetivos deste estudo - que contivessem, na ementa, os descritores eleitos para a situação de interesse. Foram excluídos acórdãos que não abordassem especificamente a questão em análise.

Realizada a busca com os descritores mencionados, retornaram inicialmente 292 documentos. Em uma segunda etapa, em que foi analisado o conteúdo de cada decisão, em seu inteiro teor, foram selecionados somente os documentos que diziam respeito especificamente ao objeto da pesquisa, excluindo-se todos os casos em que a questão não era efetivamente enfrentada e decidida pelos magistrados. Com base nesse critério, foram excluídos 118 documentos, restando 174 documentos a serem estudados. Em uma terceira etapa, analisaram-se com mais cuidado e reflexão o conteúdo e a argumentação de cada uma das decisões selecionadas, das quais 146 foram pelo deferimento do pedido, enquanto apenas 28 foram pelo indeferimento.

${ }^{13}$ Conforme metodologia descrita por SIMAS, Luciana; VENTURA, Miriam; BAPTISTA, Michelly Ribeiro; LAROUZÉ, Bernard. A jurisprudência brasileira acerca da maternidade na prisão. Revista Direito GV, São Paulo, v. 11, n. 2, p. 547-572, dez. 2015. Disponível em: <http://bibliotecadigital.fgv.br/ojs/index.php/ revdireitogv/article/view/58122/56587>. Acesso em: 02 jan. 2017. http://dx.doi.org/10.1590/18082432201524. 


\section{Resultados}

A Tabela 1 e o Gráfico 1 ilustram os resultados obtidos com a técnica de pesquisa descrita. A partir da simples observação dos resultados, podem-se extrair, desde já, as seguintes informações: (a) em todos os tribunais de justiça pesquisados, há uma forte tendência a se deferir o fornecimento do medicamento prescrito, ainda que sem registro ou autorização da Anvisa; (b) a questão foi observada, com maior incidência, nos julgados do Tribunal de Justiça do Estado do Rio Grande do Sul (TJRS).

Tabela 1. Respostas dos tribunais selecionados às demandas judiciais sobre o fornecimento de medicamento sem registro ou autorização da Anvisa

\begin{tabular}{lccccc}
\hline & $\begin{array}{c}\text { Total de } \\
\text { documentos } \\
\text { retornados } \\
\text { inicialmente }\end{array}$ & $\begin{array}{c}\text { Documentos } \\
\text { excluídos }\end{array}$ & $\begin{array}{c}\text { Documentos } \\
\text { utilizados }\end{array}$ & Deferimentos & Indeferimentos \\
\hline TJRJ & 46 & 33 & 13 & 12 & 1 \\
TJSP & 79 & 30 & 49 & 47 & 2 \\
TJMG & 50 & 20 & 30 & 20 & 10 \\
TJRS & 117 & 35 & 82 & 67 & 15 \\
\hline Totais & $\mathbf{2 9 2}$ & $\mathbf{1 1 8}$ & $\mathbf{1 7 4}$ & $\mathbf{1 4 6}$ & $\mathbf{2 8}$ \\
\hline
\end{tabular}

Legenda: TJRJ: Tribunal de Justiça do Estado do Rio de Janeiro; TJSP: Tribunal de Justiça do Estado de São Paulo; TJMG: Tribunal de Justiça do Estado de Minas Gerais; TJRS: Tribunal de Justiça do Estado do Rio Grande do Sul.

Elaboração do autor.

(\%)

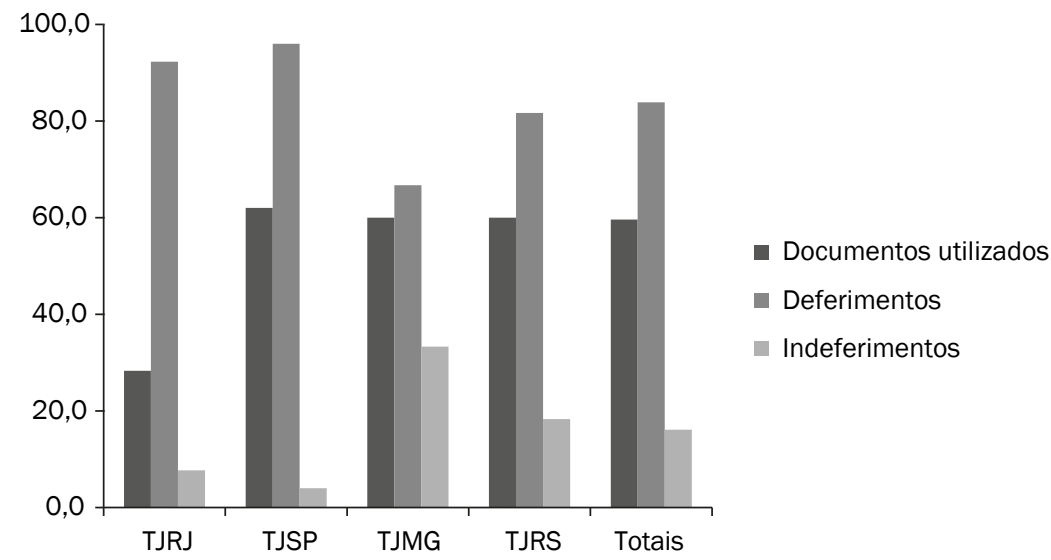

Legenda: TJRJ: Tribunal de Justiça do Estado do Rio de Janeiro; TJSP: Tribunal de Justiça do Estado de São Paulo; TJMG: Tribunal de Justiça do Estado de Minas Gerais; TJRS: Tribunal de Justiça do Estado do Rio Grande do Sul.

Elaboração do autor.

Gráfico 1. Respostas dos tribunais selecionados às demandas judiciais sobre o fornecimento de medicamento sem registro ou autorização da Anvisa 


\section{Discussão}

\section{Análise dos resultados obtidos em relação ao Tribunal de Justiça do Estado do Rio de Janeiro (TJRJ)}

No âmbito do TJRJ, as decisões que deferiram o fornecimento aduziram, basicamente, que o direito fundamental à saúde é garantido pela $\mathrm{CF} / 1988$ e que o medicamento, ainda que não possua registro na Anvisa e desde que prescrito por médico da rede pública de saúde, deve ser fornecido pelo poder público, uma vez que o médico que acompanha o paciente é a pessoa mais indicada para definir o que é melhor para a saúde do requerente ${ }^{14}$. Ou seja, nesse tribunal, os juízes, de uma forma geral, abstêm-se de discutir concretamente o eventual risco à saúde do usuário provocado pelo fornecimento de medicamento sem registro na Anvisa e o evidente descumprimento da lei, aduzindo, simplesmente, que não cabe ao Poder Judiciário imiscuir-se em questões atinentes ao exercício da medicina. Note-se que os juízes vêm simplesmente ignorando a Súmula n. 180 do próprio Tribunal, aprovada em 22 de novembro de 2010 e que assim dispõe:

A obrigação dos entes públicos de fornecer medicamentos não padronizados, desde que reconhecidos pela Anvisa e por recomendação médica, compreende-se no dever de prestação unificada de saúde e não afronta o princípio da reserva do possível ${ }^{15}$. (Destaques nossos)

Verificou-se, assim, que as decisões que deferem medicamentos nessas condições, no âmbito do Tribunal de Justiça do Estado do Rio de Janeiro, apresentam fortes indícios de interferência de convicções morais dos magistrados, que se abstêm do enfrentamento técnico-jurídico do caso concreto, optando por uma argumentação fortemente lastreada em princípios gerais e formulações genéricas.

\section{Análise dos resultados obtidos em relação ao Tribunal de Justiça do Estado de São Paulo (TJSP)}

No âmbito da corte paulista, verificou-se que algumas decisões que deferiram o fornecimento de medicamentos sem registro na Anvisa pautaram-se basicamente em princípios constitucionais. Assim, adotaram a tese de que

\footnotetext{
${ }^{14}$ São elucidativos, neste sentido, os seguintes julgados: TJRJ - QUINTA CÂMARA CÍVEL - APELAÇÃO CÍVEL - Processo n. 0058508-77.2013.8.19.0001 - Relator Desembargador Heleno Ribeiro Pereira Nunes julgamento: 13/10/2015; TJRJ - OITAVA CÂMARA CÍVEL - APELAÇÃO CÍVEL/REEXAME NECESSÁRIO - Processo n. 0002796-67.2014.8.19.0066 - Relatora Desembargadora Mônica Maria Costa Di Piero - julgamento: 05/10/2015; TJRJ - QUINTA CÂMARA CÍVEL - APELAÇÃO CÍVEL - Processo n. 0013324-96.2008.8.19.0026 - Relator Desembargador Heleno Ribeiro Pereira Nunes - julgamento: 18/08/2015; TJRJ - DÉCIMA SÉTIMA CÂMARA CÍVEL - APELAÇÃO CÍVEL - Processo n. 0002796-67.2014.8.19.0066 - Relatora Desembargadora Marcia Ferreira Alvarenga- julgamento: 31/08/2015.

${ }^{15}$ TJRJ. Súmula n. 180. Disponível em: <http://portaltj.tjrj.jus.br/documents/10136/18187/sumulas. pdf?=16>. Acesso em: 27 jan. 2017.
} 
os princípios da dignidade da pessoa humana (CF/1988, art. $1^{\circ}$, III) e da preservação da saúde dos cidadãos em geral (CF/1988, art. 6º ) estariam a impor ao Estado a obrigação de fornecer prontamente o medicamento necessitado em favor de pessoa hipossuficiente, sob responsabilidade solidária dos entes públicos (CF/1988, art. 196). Apontaram, ainda, que, em virtude da imposição constitucional de tutela do mínimo existencial, não se justificaria inibição à efetividade do direito à saúde sob os escudos de falta de padronização ou de inclusão do bem em lista oficial. Assim, a ausência de registro na Anvisa não poderia impedir o fornecimento do medicamento necessitado ${ }^{16}$.

Observou-se também em vários julgados ${ }^{17}$ que, apesar da legislação em vigor, os desembargadores chegaram a assinalar que "o fato de a medicação não ter registro na Anvisa é irrelevante, não podendo ser motivo impeditivo para o seu fornecimento" (destaques nossos). Em outra oportunidade, o tribunal decidiu que "o dever do Estado de garantir a saúde pública não se limita ao uso de medicamentos devidamente homologados pelo Ministério da Saúde" (destaques do autor) ${ }^{18}$. Ainda, em um dos dois casos de indeferimento, o tribunal ressaltou que, embora fosse possível admitir o fornecimento de medicamento sem registro no país, a situação no caso concreto era diversa, já que o fármaco em questão fora proibido de ser comercializado no Brasil ${ }^{19}$.

As decisões acima, em especial aquelas que garantiram o direito ao fornecimento de medicamentos nessas condições, afastaram a aplicação da lei, sem maiores preocupações com a elaboração de uma fundamentação efetivamente jurídica. Ao revés, os juízes utilizaram, na maior parte dos casos, um discurso tipicamente

\footnotetext{
${ }^{16}$ Nesta linha de argumentação, foram colhidos os seguintes julgados: TJSP - $1^{\text {a }}$ Câmara de Direito Público - Apelação e Reexame Necessário- Processo n. 0010517-51.2014.8.26.0268 - Relator Desembargador Vicente de Abreu Amadei - julgamento: 27/09/2016; TJSP - 9a Câmara de Direito Público - Agravo Regimental- Processo n. 2024190-37.2016.8.26.0000 - Relator Desembargador José Maria Câmara Junior - julgamento: 17/08/2016; TJSP - $13^{a}$ Câmara de Direito Público - Apelação - Processo n. 1001057 27.2015.8.26.0514 - Relator Desembargador Djalma Lofrano Filho - julgamento: 15/06/2016; TJSP - $1^{\text {a }}$ Câmara de Direito Público - Agravo de Instrumento - Processo n. 2035386-04.2016.8.26.0000 - Relator Desembargador Rubens Rihl - julgamento: 26/04/2016.

${ }^{17}$ Verifiquem-se os seguintes arrestos: TJSP - $3^{\text {a }}$ Câmara de Direito Público - Agravo de Instrumento - Processo n. 2256087-36.2015.8.26.0000 - Relator Desembargador Camargo Pereira - julgamento: 13/02/2016; TJSP - 13 ${ }^{a}$ Câmara de Direito Público - Apelação e Reexame Necessário - Processo n. 003337054.2013.8.26.0053 - Relator Desembargador Spoladore Dominguez - julgamento: 11/11/2015;TSSP - 13a Câmara de Direito Público - Apelação - Processo n. 1044944-23.2014.8.26.0053 - Relator Desembargador Ferraz de Arruda - julgamento: 02/09/2015; TJSP - 6 a Câmara de Direito Público - Agravo de Instrumento - Processo n. 2107847-08.2015.8.26.0000 - Relator Desembargador Sidney Romano dos Reis - julgamento: 29/06/2015; TJSP - 6 a Câmara de Direito Público - Agravo de Instrumento - Processo n. 2000348-62.2015.8.26.0000 - Relator Desembargador Sidney Romano dos Reis - julgamento: 22/06/2015; TJSP - $13^{\text {a }}$ Câmara de Direito Público - Agravo de Instrumento - Processo n. 221578414.2014.8.26.0000 - Relator Desembargador Ferraz de Arruda - julgamento: 25/03/2015.

${ }^{18}$ TJSP - 6 ${ }^{a}$ Câmara de Direito Público - Apelação - Processo n. 1035216-38.2014.8.26.0576 - Relator Desembargador Sidney Romano dos Reis - julgamento: 27/06/2016.

${ }^{19}$ TJSP - $13^{\text {a }}$ Câmara de Direito Público - Agravo Interno- Processo n. 2087970-48.2016.8.26.0000 - Relator Desembargador Djalma Lofrano Filho - julgamento: 06/07/2016.
} 
moral, arraigado em formulações genéricas e princípios gerais, claramente evitando o enfrentamento técnico e jurídico da questão.

\section{Análise dos resultados obtidos em relação ao Tribunal de Justiça do Estado de Minas Gerais (TJMG)}

A análise dos diversos julgados no âmbito desse tribunal revelou uma grande controvérsia sobre a questão, apesar da evidente superioridade numérica dos acórdãos no sentido de deferir o fornecimento, como se pode verificar na Tabela 1. Isso porque, em várias oportunidades, deferindo ou indeferindo o medicamento requerido, os juízes divergiram, registrando-se a existência de votos vencidos (decisões não unânimes). A título de exemplo, resgata-se o julgado mais recente do TJMG dentro do período em análise, em que o voto vencedor pelo deferimento limitou-se a uma fundamentação genérica, de caráter exclusivamente moral, ressaltando que "a saúde é direito fundamental para a preservação da vida" ${ }^{20}$ e que caberia ao Estado promover meios para sua realização. Em acréscimo, registrou que o direito do cidadão deve ser amplo e integral, de forma que, uma vez recomendado determinado procedimento como o mais adequado para o caso específico, seu fornecimento não pode ser negado ou condicionado ${ }^{21}$. Observe-se que os juízes esquivaram-se de enfrentar a questão de forma técnica, optando por uma argumentação tão vaga e imprecisa, que poderia ser utilizada, inclusive, para diversas outras situações.

Já o voto vencido indeferia o fornecimento do medicamento com efetiva fundamentação calcada em argumentação técnico-jurídica, enfrentando, precisamente, a questão legal e a questão de saúde envolvidas:

\footnotetext{
${ }^{20}$ TJMG - Agravo de instrumento - Processo n. 0520260-48.2016.8.13.0000 - Relatora Desembargadora Heloisa Combat - julgamento: 01/12/2016. Registramos outros julgados em que a questão foi objeto do mesmo debate e controvérsia entre os juízes, tendo sido,igualmente, decidida por maioria: TJMG - Agravo de instrumento - Processo n. 0648680-71.2016.8.13.0000 - Relatora Desembargadora Heloisa Combat - julgamento: 01/12/2016; TJMG - Agravo de instrumento - Processo n. 0756917-39.2015.8.13.0000Relator Desembargador Luís Carlos Gambogi - julgamento: 07/07/2016;TJMG - Apelação Cível e Reexame Necessário - Processo n. 0199127-80.2009.8.13.0028- Relatora Desembargadora Ângela de Lourdes Rodrigues - julgamento: 16/12/2015;TJMG - Agravo de instrumento - Processo n. 096848687.2014.8.13.0000- Relator Desembargador Raimundo Messias Júnior - julgamento: 21/07/2015; TJMG - Agravo de instrumento - Processo n. 0888243-59.2014.8.13.0000- Relator Desembargador Carlos Levenhagen - julgamento: 07/05/2015.

${ }^{21}$ TJMG - Agravo de instrumento - Processo n. 0520260-48.2016.8.13.0000 - Relatora Desembargadora Heloisa Combat - julgamento: 01/12/2016. Registramos outros julgados em que a questão foi objeto do mesmo debate e controvérsia entre os juízes, tendo sido,igualmente, decidida por maioria: TJMG - Agravo de instrumento - Processo n. 0648680-71.2016.8.13.0000 - Relatora Desembargadora Heloisa Combat - julgamento: 01/12/2016; TJMG - Agravo de instrumento - Processo n. 0756917-39.2015.8.13.0000Relator Desembargador Luís Carlos Gambogi - julgamento: 07/07/2016;TJMG - Apelação Cível e Reexame Necessário - Processo n. 0199127-80.2009.8.13.0028- Relatora Desembargadora Ângela de Lourdes Rodrigues - julgamento: 16/12/2015;TJMG - Agravo de instrumento - Processo n. 096848687.2014.8.13.0000- Relator Desembargador Raimundo Messias Júnior - julgamento: 21/07/2015; TJMG - Agravo de instrumento - Processo n. 0888243-59.2014.8.13.0000- Relator Desembargador Carlos Levenhagen - julgamento: 07/05/2015.
} 
[...] Não se pode, sob o pretexto de dar efetividade ao direito constitucional à saúde, determinar fornecimento de medicamento que não goza de consenso científico, revelado mediante o registro do produto - exigido em preceito legal - no órgão público competente, sob pena de autorizar o experimentalismo farmacêutico às expensas da sociedade, que financia a saúde pública por meio de impostos e contribuições, além do risco de prejudicar a saúde do paciente $[\ldots]^{22}$. (Destaques nossos)

Observaram-se, ainda, outros julgados em que o fornecimento fora deferido em decisão unânime, ao argumento de que o registro do medicamento junto à Anvisa e às listas administrativas de dispensação geridas pelos SUS não constitui requisito absoluto para o fornecimento do fármaco pelo ente público, podendo ser afastado diante das peculiaridades do caso concreto, em particular a inexistência de outra alternativa terapêutica e a constatação de risco de vida ${ }^{23}$.

Além da forte divergência de entendimentos entre os juízes, constatou-se no tribunal mineiro a utilização de argumentação genérica e evasiva nas decisões que deferiram o fornecimento de medicamentos, caracterizando, como nas demais cortes já analisadas, a interferência de convicções morais dos magistrados ao decidirem sobre a questão em evidência.

\section{Análise dos resultados obtidos em relação ao Tribunal de Justiça do Estado do Rio Grande do Sul (TJRS)}

Prevalece, na corte, tendência ao deferimento dos medicamentos requeridos sob tais condições, aos argumentos de que "a ausência de registro dos fármacos junto à Anvisa não pode ser utilizada para justificar gestões ineficientes” e de que

\footnotetext{
${ }^{22}$ TJMG. Disponível em <http://www5.tjmg.jus.br/jurisprudencia/pesquisaPalavrasEspelhoAcordao.do?nu meroRegistro=1\&totalLinhas $=1 \&$ palavras $=$ medicamento $+e+$ registro $+e+a n v i s a+e+f o r n e c i m e n t o+e+p \%$ FAblico\&pesquisarPor=ementa\&pesquisaTesauro=true\&orderByData=1\&codigoOrgaoJulgador=\&codigo CompostoRelator $=\&$ dataPublicacaolnicial $=$ \&dataPublicacaoFinal=\&dataJulgamentolnicial $=01 \% 2 \mathrm{F0} \%$ 2F2014\&dataJulgamentoFinal=31\%2F12\%2F2016\&siglaLegislativa=\&referenciaLegislativa=Clique+na +lupa+para+pesquisar+as+refer\%EAncias+cadastradas...\&numeroRefLegislativa=\&anoRefLegislativa= \&legislacao=\&norma=\&descNorma=\&complemento_1=\&listaPesquisa=\&descricaoTextosLegais=\&obs ervacoes=\&linhasPorPagina=10\&pesquisaPalavras=Pesquisar $>$. Acesso em: 28 jan. 2017.

${ }^{23}$ São os seguintes: TJMG - Apelação Cível - Processo n. 0075801-64.2013.8.13.0183 - Relatora Juíza Convocada Claret de Moraes - julgamento: 01/03/2016;TJMG - Apelação Cível - Processo n. 000564908.2011.8.13.0879 - Relatora Juíza Convocada Claret de Moraes - julgamento: 20/10/2015;TJMG - Agravo de Instrumento - Processo n. 0653297-11.2015.8.13.0000 - Relatora Desembargadora Sandra Fonseca - julgamento: 20/10/2015; TJMG - Apelação Cível e Reexame Necessário - Processo n. 0052947-44.2008.8.13.0024 - Relatora Juíza Convocada Claret de Moraes - julgamento: 08/09/2015; TJMG - Apelação Cível - Processo n. 0012309-46.2013.8.13.0362 - Relatora Juíza Convocada Claret de Moraes - julgamento: 11/08/2015; TJMG - Agravo de Instrumento - Processo n. 0958985-12.2014.8.13.0000 - Relator Desembargador Washington Ferreira - julgamento: 14/07/2015.
} 
“as políticas públicas que não concretizam os direitos fundamentais inerentes à dignidade da pessoa humana desatendem o mínimo existencial, assegurado pela Carta Magna"24.

\section{Também houve deferimentos ao argumento de que, embora}

[...] não seja de praxe o fornecimento de medicamento que não possua registro na Anvisa, em situações excepcionais, quando devidamente comprovada a necessidade de o paciente fazer uso em face de risco de vida, esta Corte de Justiça tem relativizado tal restrição $0^{25}$.

Por outro lado, as decisões que indeferiram o fornecimento o fizeram ao argumento de que não restara demonstrado que o fármaco postulado - que não possui registro na Anvisa - fosse a única opção possível para manutenção da saúde do paciente ${ }^{26}$.

\footnotetext{
${ }^{24}$ Entre outros, verifiquem-se os seguintes julgados: TJRS - Primeira Câmara Cível - Apelação Cível - Processo n. 70070877808 - Relator Desembargador Sergio Luiz Grassi Beck- julgamento: 30/09/2016;TJRS - Primeira Câmara Cível - Apelação Cível - Processo n. 70070854328 - Relator Desembargador Sergio Luiz Grassi Beck- julgamento: 14/09/2016;TJRS - Primeira Câmara Cível - Apelação Cível - Processo n. 70070457155 Relator Desembargador Sergio Luiz Grassi Beck- julgamento: 09/08/2016; TJRS - Primeira Câmara Cível Apelação Cível - Processo n. 70070044144 - Relator Desembargador Sergio Luiz Grassi Beck- julgamento: 07/07/2016; TJRS - Primeira Câmara Cível -Apelação e Reexame Necessário - Processo n. 70069625960 Relator Desembargador Sergio Luiz Grassi Beck- julgamento: 15/06/2016; TJRS - Primeira Câmara Cível Apelação Cível - Processo n. 70069275295 - Relator Desembargador Sergio Luiz Grassi Beck- julgamento: 01/06/2016;TJRS - Primeira Câmara Cível - Apelação e Reexame Necessário- Processo n. 70067234880 Relator Desembargador Sergio Luiz Grassi Beck- julgamento: 01/06/2016; TJRS - Primeira Câmara Cível - Apelação Cível - Processo n. 70068314871 - Relator Desembargador Sergio Luiz Grassi Beckjulgamento: 03/03/2016; TJRS - Primeira Câmara Cível - Apelação Cível - Processo n. 70067995258 Relator Desembargador Sergio Luiz Grassi Beck- julgamento: 02/03/2016; TJRS - Primeira Câmara Cível - Apelação e Reexame Necessário- Processo n. 70066734484 - Relator Desembargador Sergio Luiz Grassi Beck- julgamento: 13/10/2015; TJRS - Primeira Câmara Cível - Apelação Cível - Processo n. 70066734104 Relator Desembargador Sergio Luiz Grassi Beck- julgamento: 05/10/2015.

${ }^{25}$ Nesse sentido: TJRS - Segunda Câmara Cível - Apelação e Reexame Necessário - Processo n. 70071210017 - Relatora Desembargadora Lúcia de Fátima Cerveira - julgamento: 26/10/2016; TJRS - Segunda Câmara Cível - Apelação Cível - Processo n. 70070352257 - Relatora Desembargadora Lúcia de Fátima Cerveira - julgamento: 28/09/2016; TJRS - Vigésima Segunda Câmara Cível - Apelação Cível - Processo n. 70070073366 - Relator Desembargador José Aquino Flôres de Camargo - julgamento: 28/07/2016; TJRS - Segunda Câmara Cível - Apelação e Reexame Necessário - Processo n. 70069811909 - Relatora Desembargadora Lúcia de Fátima Cerveira - julgamento: 27/07/2016; TJRS - Vigésima Segunda Câmara Cível - Apelação Cível - Processo n. 70068282052 - Relatora Desembargadora Lúcia de Fátima Cerveira - julgamento: 25/02/2016; TJRS - Sétima Câmara Cível - Apelação e Reexame Necessário Processo n. 70068321074 - Relatora Desembargadora LiselenaSchifino Robles Ribeiro - julgamento: 18/02/2016; TJRS - Sétima Câmara Cível - Agravo Interno- Processo n. 70066517848 - Relatora Desembargadora LiselenaSchifino Robles Ribeiro - julgamento: 30/09/2015.

${ }^{26}$ Verifiquem-se os seguintes julgados: TJRS - Quarta Câmara Cível - Agravo de Instrumento - Processo n. 70065881450 - Relator Desembargador Eduardo Uhlein - julgamento: 18/11/2015; TJRS - Quarta Câmara Cível - Agravo de Instrumento - Processo n. 70063337224 - Relator Desembargador Francesco Conti - julgamento: 29/04/2015; TJRS - Quarta Câmara Cível - Agravo de Instrumento - Processo n. 70061799292 - Relator Desembargador Eduardo Uhlein - julgamento: 26/11/2014; TJRS - Quarta Câmara Cível - Agravo de Instrumento - Processo n. 70058300807 - Relator Desembargador Eduardo Uhlein - julgamento: 23/04/2014.
} 
A jurisprudência do TJRS indica que, nos casos de deferimento, os juízes com frequência utilizaram formulações genéricas e princípios gerais do Direito, ao passo que, ao indeferirem, fundamentaram suas decisões de forma técnica, questionando a ausência de prova da efetiva necessidade de se recorrer ao medicamento sem registro na Anvisa.

\section{Considerações finais}

A dimensão empírica da pesquisa jurisprudencial permitiu averiguar como uma importante questão na área da saúde, com efetivo potencial para desafiar os juízes em suas conviç̧ões morais, vem sendo enfrentada e decidida em cada um dos tribunais selecionados. Como restou demonstrado, prevalecem, nos quatro tribunais estaduais pesquisados, decisões pelo deferimento dos medicamentos requeridos, em que pesem os aspectos legais, jurisprudenciais e de preservação da saúde envolvidos. Os juízes, via de regra, abstêm-se de enfrentar a questão de forma técnica e optam por formulações genéricas, princípios gerais etc., fazendo uso, portanto, de argumentação que revela a existência de conflitos. Eis que as decisões estão sendo proferidas, possivelmente, sob forte interferência das convicções morais e dos sentimentos pessoais de cada magistrado, daí a grande dificuldade que experimentam em fundamentá-las adequadamente, o que os leva a fazer uso de tais artifícios. No caso particular do TJMG, registrou-se uma significativa controvérsia sobre o tema, o que corrobora a conclusão de que as convicções pessoais de cada magistrado sobre o tema não devem ser, necessariamente, as mesmas.

Por derradeiro, não se pode esquecer que, em todos os casos em que o fornecimento do medicamento foi deferido, os juízes negaram aplicação à lei que exige o registro na Anvisa. Ora, os juízes, de uma forma geral, só devem negar aplicação de lei em vigor se a considerarem inconstitucional, o que deve constar expressamente dos fundamentos da decisão. Em se tratando de decisão de tribunal, como no caso, deve-se, inclusive, instaurar o incidente de arguição de inconstitucionalidade previsto no Código de Processo Civil ${ }^{27}$ (arts. 948 e 949), como, aliás, exige a Súmula n. 10 do STF:

Viola a cláusula de reserva de plenário (CF, art. 97) a decisão de órgão fracionário de Tribunal que, embora não declare expressamente a inconstitucionalidade de lei ou ato normativo do poder público, afasta sua incidência, no todo ou em parte ${ }^{28}$.

\footnotetext{
${ }^{27}$ BRASIL. Lei n. 13.105, de 16 de março de 2015. Código de Processo Civil. Disponível em: <http://www. planalto.gov.br/ccivil_03/_ato2015-2018/2015/lei/l13105.htm>. Acesso em: 27 jan. 2017.

${ }^{28}$ STF. Súmula Vinculante. Disponível em: <http://www.stf.jus.br/portal/cms/verTexto.asp?servico=jurisprud enciaSumulaVinculante>. Acesso em: 26 dez. 2016.
} 
Esse procedimento não foi observado em nenhum dos casos em que o fornecimento fora concedido, o que reforça a tese de que as deliberações dos tribunais nesse sentido vêm se pautando antes em convicções pessoais dos magistrados, afastando do debate as disposições legais e jurisprudenciais superiores pertinentes ao tema.

\section{Referências}

ATIENZA, Manuel. Razões do direito: teorias da argumentação jurídica. 3. ed. São Paulo: Landy, 2003.

BALESTRA NETO, Otávio. A jurisprudência dos tribunais superiores e o direito à saúde evolução rumo à racionalidade. Revista de Direito Sanitário, Brasil, v. 16, n. 1, p. 87-111, jul. 2015. Disponível em: <http://www.revistas.usp.br/rdisan/article/view/100025>. Acesso em: 21 jan. 2017. http://dx.doi.org/10.11606/issn.2316-9044.v16ilp87-111.

CHIEFFI, Ana Luiza; BARATA, Rita de Cássia Barradas. Ações judiciais: estratégia da indústria farmacêutica para introdução de novos medicamentos. Revista de Saúde Pública, São Paulo, v. 44, n. 3, jun. 2010. Disponível em: <http://www.scielo.br/scielo.php?script=sci_arttext\&p $\mathrm{id}=$ S0034-89102010000300005 $>$. Acesso em: 21 jan. 2017.http://dx.doi.org/10.1590/S003489102010000300005 .

DWORKIN, Ronald. A justiça de toga. São Paulo: Martins Fontes, 2010.

FREITAG, Barbara. A questão da moralidade: da razão prática de Kant à ética discursiva de Habermas. Tempo Social - Rev. Sociologia da USP, v. 1, n. 2, p. 1-32, jul./dez 1989. Disponível em: <http://www.scielo.br/scielo.php?script=sci_arttext\&pid=S0103-20701989000200007\&ln $\mathrm{g}=\mathrm{en} \& \mathrm{nrm}=\mathrm{iso}>$. Acesso em: 21 jan. 2017.http://dx.doi.org/10.1590/ts.v1i2.84764.

MINISTÉRIO DA SAÚDE. Intervenção judicial na saúde pública: panorama no âmbito da Justiça Federal e apontamentos na seara das Justiças Estaduais. Brasília-DF, 2013. Disponível em: <http://u.saude.gov.br/images/pdf/2014/maio/29/Panorama-da-judicializa----o---2012--modificado-em-junho-de-2013.pdf $>$. Acesso em: 7 jul. 2016.

POSNER, Richard A. The problematic of moral and legal theory. 3. ed. Harvard: Harvard University Press, 2009.

SIMAS, Luciana; VENTURA, Miriam; BAPTISTA, Michelly Ribeiro; LAROUZÉ, Bernard. A jurisprudência brasileira acerca da maternidade na prisão. Revista Direito GV, São Paulo, v. 11, n. 2, p. 547-572, dez. 2015. Disponível em: <http://bibliotecadigital.fgv.br/ojs/index.php/revdireitogv/ article/view/58122/56587>. Acesso em: 02 jan. 2017. http://dx.doi.org/10.1590/1808-2432201524.

VENTURA, Miriam. O processo decisório judicial e a assessoria técnica: a argumentação jurídica e médico-sanitária na garantia do direito à assistência terapêutica no SUS. Tese (Doutorado) - Escola Nacional de Saúde Pública Sergio Arouca, Rio de Janeiro, 2012. Disponível em: <http://bases.bireme.br/cgi-bin/wxislind.exe/iah/online/?IsisScript=iah/iah. xis\&src $=$ google\&base $=$ LILACS\&lang $=$ p\&nextAction $=\operatorname{lnk} \&$ exprSearch=745021\&indexSear $\mathrm{ch}=\mathrm{ID}>$. Acesso em: 10 nov. 2016. 
Decisões judiciais na saúde e convicções pessoais de cada juiz

José Carlos Zebulum - Doutorando em Saúde Pública pela Universidade Federal do Rio de Janeiro (UFRJ); mestre em Direito pela Universidade do Estado do Rio de Janeiro (UERJ); graduado em Direito pela UERJ; graduado em Engenharia Naval pela Universidade de São Paulo (USP). Professor da Fundação Educacional Serra dos Órgãos. Juiz Federal do Rio de Janeiro. Rio de Janeiro/RJ, Brasil.E-mail: jcarloszebulum@gmail.com 